\title{
Contextualizing Game Literacy
}

\author{
A transhistorical approach to understanding Game-Based Learning environments
}

\author{
Björn Berg Marklund \\ School of Informatics, University of \\ Skövde, Skövde, Sweden \\ bjorn.berg.marklund@his.se
}

\author{
Rebecca Rouse \\ School of Informatics, University of \\ Skövde, Skövde, Sweden \\ rouse.rebecca@gmail.com
}

\author{
Lissa Holloway-Attaway \\ School of Informatics, University of \\ Skövde, Skövde, Sweden \\ lissa.hollowayattaway@his.se
}

\begin{abstract}
The nature of 'reading' different types of texts, across all media, is fundamentally beholden to the concept of 'literacy'. The concept of literacy is well established in media studies-from books, to film, and visual, performing and interactive arts-and as such it has a wide range of applicability. All forms of media constitute a semiotic milieu in which signifiers and codes mean different things depending on the form's unique language and the contexts and manner in which individual participants, or "readers", approach them. In the field of digital games research, literacy is commonly defined as a narrower concept that refers to the ability to identify affordances and interact with game components with a high degree of confidence. This focus on capability is understandable to a degree: the unique aspect of games as a medium is often considered to specifically be its interactability, and thus being able to interact becomes synonymous with being 'game literate'. In this paper, however, we will both describe how literacy in games would benefit from a more nuanced, transhistorical view of interactability, as well as provide examples from many kinds of media beyond games to demonstrate that interaction literacy is neither novel nor unique to the medium of games. Understanding this rich history would provide a broader foundation of referential literature for game scholars to use when discussing the concept of game literacy and the interactability of media in general.
\end{abstract}

\section{KEYWORDS}

Game literacy, game-based learning, transhistorical, somatic experience, interactive immersive environments, storyworld design

\section{ACM Reference Format:}

Björn Berg Marklund, Rebecca Rouse, and Lissa Holloway-Attaway. 2020. Contextualizing Game Literacy: A transhistorical approach to understanding Game-Based Learning environments. In International Conference on the Foundations of Digital Games (FDG '20), September 15-18, 2020, Bugibba, Malta. ACM, New York, NY, USA, 6 pages. https://doi.org/10.1145/3402942. 3409610

\section{INTRODUCTION}

What can we learn from the long history of interactive literacies to support design with interactive games technologies? This paper

Permission to make digital or hard copies of part or all of this work for personal or classroom use is granted without fee provided that copies are not made or distributed for profit or commercial advantage and that copies bear this notice and the full citation on the first page. Copyrights for third-party components of this work must be honored.

For all other uses, contact the owner/author(s).

FDG '20, September 15-18, 2020, Bugibba, Malta

(C) 2020 Copyright held by the owner/author(s).

ACM ISBN 978-1-4503-8807-8/20/09.

https://doi.org/10.1145/3402942.3409610 examines relevant examples from antiquity to today to illuminate the complex and multi-layered functions and affordances that constitute literacy in immersive interactive learning environments. With deeper reflection on the histories of interactivity, we can see that there are a range of contributing factors that come together to co-construct a given user's literacy as they interact with, and within, the context of media engagement. These factors include the cognitive and psychological processes associated with digital literacy development (Cooper et al., 2013; Hague and Payton, 2010; Mcloughlin, 2012; Ng, 2012), the political and social contexts that influence issues of digital access (Gee and Hayes, 2011; Jenkins, 2009) and techno-cultural belonging (Wallace, 2006), as well as the nature of the interactive medium itself and the design of the particular experience. The focus of this paper is on the latter factor and examines the design of the interactive immersive spaces itself to better understand user reception, particularly as it pertains to literacy.

We also provide an examination of the alleged uniqueness of digital literacy and contextualize it by comparing it to literacies in other pre-digital immersive media forms, which is a hallmark of much research in the field. Cooper et al., 2013, for example, foreground the complexity of literacies in digital contexts, seeing it as fundamentally connected to plurality and multidimensionality. They refer then to 'multiliteracies' as a key factor unique for digital domains. Mcloughlin (2012) emphasizes multiplicity as key to digital literacies and stresses the 'multimodalities' of digital forms. Belshaw, 2012 identifies 8 intersecting "c" factors to demonstrate the multi-layered interactions specific to digital literacy, stressing how literacy is co-constructed in material, virtual, social, and personal spheres of development spaces: cognitive, constructive, communication, civic, critical, creative, confident, cultural. Our transhistorical perspective, however, focuses on interactive design with pre-digital media in immersive environments, suggesting there is a much longer legacy from which we may consider the complex nature of player literacy and, in particular, its relevance to game-based learning.

Immersive learning environments may at first seem like a wholly new phenomenon unique to the digital games medium and even enhanced by new technologies such as Virtual or Augmented Reality. However, it is important to look to the past for antecedents which can not only help in the interpretation of works made today but also provide a rich source of inspiration and reflection. In contextualizing our work as part of a longer trajectory, we also push back against the commonly made claims that interaction in digital media (and particularly games) is somehow uniquely "new" and incomparable to prior forms, thus seeking to examine areas of continuation and expansion. With this in mind, we investigate 
and contrast examples of interactive and immersive experiences and the various elements that define spatial storyworlds and user meaning-making within these worlds across media.

\section{LITERACY IN DIGITAL GAME STUDIES}

Descriptions of literacy in game studies rarely focus on the numerous spatial qualities of the immersive environment, or players' active meaning-making within these spaces, and instead focus on properties of a rule-based system. Spatial qualities of games as understood through an experiential perspective are somewhat under-researched, with a few notable exceptions (von Borries et al., 2007; Nitsche, 2008; Schweizer, 2009, 2013, 2014). And so perhaps unsurprisingly, the instrumentalized and utilitarian nature of digital game literacy is a recurring element in the rhetorics frequently used in scholarly works, and the disproportionally few papers that object to this focus.

Digital Game-Based Learning might be the subfield of games studies in which literacy is most intensely discussed. A good place to start unpacking this discussion is to look at seminal works from the 00's when Digital Game-Based Learning, leaning on previous work on educational games and edutainment, established itself under its new moniker. The foundation of the field's past and contemporary rhetorics, and its implicit skew towards implicit instrumentalism, is evident in the work of Prensky (2001), Gee, 2003, and Bogost (2007) who theorize ontologies of games as tools, semiotic domains respectively, and procedural systems.

For Prensky (2001), game literacy comes down to a mystical natural game proficiency held by the generation of users that are presumed to interact with games and technology the most. Games are distilled into a combination of learning properties and engaging properties, and literacy is primarily seen as the ability to access the engaging processes and by doing so learning happens as a side effect. Games are instruments for learning, and more specifically, far superior instruments to the ones used in 'traditional education'. Very little of this superiority is anchored in the actual application of content literacy inside the games, but rather the newer generations' unwavering lust to play and beat games. Prensky frequently refers to 'gaming literacy', especially in relation to the term 'digital native'. The digital native is, shortly summarized, a person born in the 'internet era' and has thus grown up surrounded by technology and digital games. According to Prensky, their brains work fundamentally differently from previous generations, and it is imperative that we package any form of information into games if we want to reach this new game literate generation: "[...] the native Games Generation is cognitively different from its predecessors, whether digital immigrants or not. [...] the many skills that new technologies have actually enhanced (e.g., parallel processing, graphics awareness, and random access)" (Prensky, 2001).

For Prensky, literacy is essentially equated to motor skills, cognitive processing, and ability to rapidly 'scan' virtual spaces. Eck (Van Eck, 2006), heavily referencing Prensky, exemplifies this by describing the digital native as having immense 'visual literacy' skills (Eck, Van Eck, 2006). In short, digital game-based learning originates in this discourse that defines literacy as an ability to interact with an instrument, and further defines this ability as 'native' instilled in a person from birth.
Bogost (2007) has an approach that diverges from equating literacy with the ability to access information, to a form of "rules first" description of game literacy and meaning-making. This is not only evident in the title of the book in which he outlines his approach to meaning-making in games, Persuasive Games: The Expressive Power of Video Games, but also in his language: "As cultural critics, we can interrogate literature, art, film, and daily life for the underlying processes they trace. But computational procedurality places a greater emphasis on the expressive capacity afforded by rules of execution" (Bogost, 2007 p. 4-5).

In essence, Bogost attributes much of the meaning-making in games to the designers' intent and their writing of the game 'text' in the form of procedural system design. This is done at the expense of the processes of 'reading' as performed by the player (i.e., exercising individual literacy). In this model, players' literacy is what helps them see the game rules and come to understand the designer's message, but not so much the ability to contribute their own interpretations to it. Games persuade the player through their interaction with rules, but there is little room for the player's actual reading of the content or the complex, negotiated interpreted flows of reception as, for example, described by Stuart Hall, 1980.

Gee's theory (Gee, 2003) lies somewhere between Bogost and Prensky, but focuses significantly more on literacy in particular. This is evident in the title of his oft cited book What Video Games Have to Teach Us about Learning and Literacy, as well as its contents. For Gee, the notion of interactive spaces does become more prominent; games constitute an 'environment' of meaning and symbols, and a person needs to learn the semiotics of this environment to navigate it. The process of forming a literacy within the space is, however, similarly to Prensky in that it is considered to be expressed in ability to execute certain actions and quickly identifying games' various affordances. Games provide rules of interaction, and a player developing an ability to cooperate with the rules is equated to learning. This stance is made clearer in his subsequent publications, such as Learning by Design: Good Video Games as Learning Machines (Gee, 2005), where the title itself encapsulates the "games induce learning" approach to understanding meaning-making in games.

While Gee's position is a bit more complex than the previous examples as it encapsulates both the reader and the text. But, perhaps due to his background as a cognitive scientist, Gee approaches literacy in as information processing, and designers' intent (i.e., what information they choose to provide) is still key: "There are many good principles of learning built into good computer and video games. [...] The stronger any game is on more of the features on the list, the better its score for learning" (Gee, 2003, p.17).

Gee also contrasts specific types of games against others to describe what types of literacies they develop in their players. Some games are considered to be 'dumbed down,' whereas games that are considered to be more "valuable" from a literacy standpoint are more complex and difficult (Gee, 2003, p.15). It is strongly insinuated that a game that can be beaten by, for example, older people or casual players, provide little in terms of literacy development. In one of the early academic texts on educational games, Malone, 1980 bases his discussion regarding the meaning-making in games exclusively on game design and game properties. A game including elements of randomness, clear feedback, well balanced difficulty, 
rewards, and high quality audio and visual stimulation will be a good learning instrument (Malone, 1980).

These works exemplify how game literacy is beholden to the intended meaning conveyed by digital technologies, rules, and game mechanics, and literacy is the players' ability to interact with these objects and systems to access this meaning. Rather than being created through dialogue between 'text' and its 'reader', meaning is automatically inflicted on the player during game traversal. These oversights present in much of 00's game studies are highlighted in later works, e.g., Sicart, 2011, but also works from the same period, e.g., Carr, 2007 and Buckingham and Burn, 2007. Carr questions the over-emphasis placed on the rule (or, 'ludic') components of a game at the expense of the dialogue of playfulness as a form of active performance (or, 'paidea'). Carr both argues against the use of the ludic 'rules first' approach as well as the 'literacy is ability to play' approach when describing how meaning is formed through games. In this particular discussion, the game Civilization III (or, Civ) serves as the exemplifying object: "I would stress that the point is not that either the novice or the expert is more 'right' about the meaning of Civ. [...] Furthermore, this shows that the meaning of Civilization - whatever it might be - is neither universal, nor static." (Carr, 2007)

Carr both critiques Gee's notions of literacy being defined by players' expertise, as well as the instrument-focused meaningmaking described by Bogost. The same critique against a 'rules first' approach to understand how games are 'read' is echoed in Sicart, 2011, who specifically takes a stance against the 'proceduralist approach' (referring to Bogost's 'procedural rhetorics'): “[...] in the proceduralist tradition, play is not central to understanding the meanings created by (playing) games, since it is the rules that create those meanings." (Sicart, 2011)

In short, the 'rules first', or perhaps more suitably 'instrument first', approach to understanding games and literacy/learning by necessity has to reduce the importance of the 'readers' themselves. This reduction leads to simplification; scholars as well as designers often write about game interactions with an assumed "rational" player that behave in a predictable way. Players are assumed to read presented content as the researcher or designer have planned, and there is little room for more nuanced discussions regarding the thought processes and contexts of play of the individual player.

More insidious, the cultural imagination around who a player might be is often disappointingly narrow and reflective of oppressive dominant narratives. These narratives have been formed in a period where the medium founds its "voice", which happens to coincide with a development of a cultural narrative of games being made for, and meant to be consumed by, adolescent men; and women were reduced to trophies or nurturing mother figures (Kirkpatrick, 2017). This cultural narrowing influences designers as well, who in many cases do not consider how player positionality may impact meaning-making. As phrased by Sicart:

Game designers are supposed to create play, that is, a particular behavior in players. Proceduralists believe that those behaviors can be predicted, even contained, by the rules, and therefore the meaning of the game, and of play, evolves from the way the game has been created and not how it is played; not to mention when and where it is played, and by whom. (Sicart, 2011)

In summary, the discussion regarding literacy in game studies tends to over-emphasize the importance of the game's rules and authorial intent, and it focuses instead on an ontology of games that values instrumentality and abstraction. Related to this instrumentalist approach to understanding games, the players' literacy that makes it possible to 'read' games is thus also reduced to their ability to access these abstracted rules and arrive at a 'correct,' ideal or singular interpretation of the game experience. In contrast, we present a discussion of literacies in interactive immersive spaces as co-constructed to tease out a more deeply layered view of player literacy, beyond instrumentality and singularity.

\section{A BRIEF HISTORY OF INTERACTIVE IMMERSIVE STORYWORLDS}

This brief history is by no means comprehensive, but instead represents a curated set of examples from a range of time periods that connect in interesting ways with how literacy is defined in relation to digital games. Each example provides a historical look back to another time and technology in which people engaged interactive storytelling and physical space or representations of space. Just as games are often (but not always) organized around metaphors of physical space, territories, maps, and storyworlds that are traversed by participants, these historical examples also present interactive storytelling situated in space. While the spatial qualities of games have been insightfully critiqued by Mukherjee and others for their enduring colonialist traces (Mukherjee, 2017) in that they often include elements of inhabiting and subsequently conquering or using agency to create different forms of ownership, the focus in our analysis is instead on unpacking the somatic and interpretive experience of the participant.

In one of our earlier examples, we look at Matthew Paris' Itinerary Maps from London to Palestine. Paris, a monk at the Abbey of St. Alban in England, created a series of manuscripts around 1250 that included itineraries of pilgrimage routes to Palestine. The maps in these manuscripts included flaps that could fold out from the page, allowing the reader to interactively simulate different itineraries along a route through several major European cities (Crupi, 2019: 5). Paris himself had never made the pilgrimage journey, and it is not clear how he obtained the information to map these routes. It is also worth emphasizing that these books, while in the codex form (a series of parchment pages bound at one edge) were not printed but handwritten, and thus part of the earlier manuscript culture. It is interesting to see that even at this early point in the history of the codex form prior to the age of print, we can find interactivity, meaning the supposedly passive book reader has always already been an interactor even in the literal sense. In imagining the reader of these volumes, it is possible the map representation does not function cartographically, but as a virtual representation of the journey, for the reader to take with eye and hand instead of by foot. As the readers of these books were most likely fellow monks, and not necessarily able to make the sacred journey in person, the spatialized interactive narrative of the pilgrimage in these works was likely intended as a spiritual tool 
to assist the reader in his devotional travels of a holy nature (Crupi, 2016: 28).

Related to this example but expanded beyond the bounds of the page and representational space into three dimensionality at human scale, we find the tradition of the Sacri Monti or sacred mountains in Italy in the 16th and 17th centuries. These were mountaintop complexes built with a series of chapels, each dedicated to telling a particular moment in the story of Christ. These complexes were designed as a kind of virtual pilgrimage for the faithful to make, even when they could not travel all the way to the holy land. Situated on mountaintops, these themed environments crucially included the experience of physical exertion in climbing to their peaks and visiting each chapel. Chapels were intricately designed, often on a site plan layout intended to simulate or mirror the locations of episodes in Christ's life, with interior frescoes and three-dimensional life sized wooden and terracotta figures fully costumed and positioned as acting out key moments from the biblical text. The earliest of these Sacri Monti was the Sacro Monte di Varallo in northern Italy, established in 1491. While the site was not designed for independent navigation - the pilgrim's path was guided and narrated by friars who operated the site - the interaction expected of the pilgrim was intense and active, both physically and mentally as well as spiritually, and highly proceduralized as a religious ritual.

Pilgrims were expected to begin their journey at a church at the base of the mountain, the Santa Maria delle Grazie, and then begin the steep two kilometre climb up winding paths to the top. As pilgrims moved through the multiple chapels on the mountaintop, the aim was to develop a deeper spiritual and emotional connection to Christ through sensorial, devotional experience. As described by Terry-Fritsch: "Pilgrims would configure their bodies in relation to the shifting architectural proportions of the building, bend over to accommodate low ceilings, crawl on knees to access the inner chamber, and press up against and even climb into the tomb of Christ" (Terry-Fritsch, 2014: 118). The chapel that housed the representation of the crucifixion appears to have been designed to offer a particularly immersive experience, with the pilgrims standing in among the surrounding crowds observing Christ's suffering.

Slightly earlier than the example of the Sacri Monti we could look to the tradition of the medieval mystery plays in England for another instance of interactive spatialized storytelling, this time with a participatory element. The mystery plays also served a religious function as liturgical drama, but functioned in complex social and cultural ways as well. These plays were performed on mobile pageant wagons, first decorated by statues (as in the chapels of the Sacri Monti) but later replaced by live performers. The wagons were paraded through towns, stopping at multiple outdoor locations where the performances were held. The York cycle of forty-eight plays telling stories from the old and new testament is one of the few surviving, and was first recorded as celebrating the festival of Corpus Christi in 1376.

In contrast with the Sacri Monti, which were entirely developed and overseen by the Franciscans, the York plays were organized, developed, and performed by the local craft guilds. This was prior to the development of professionalization in theatre, and so there were no professional actors, designers, or directors, and no purpose-built performance spaces. Each guild would design a pageant wagon for a scene from the play most fitting their actual craft expertise - for example, the nail makers might stage the crucifixion, while the ship builders might stage Noah's flood. Along with spoken text, the story was portrayed with music and in song. Technologically, in spite of the lack of a permanent performance space, these productions could become quite complex. Elaborate costumes, props, and masks were used including large-scale mechanically articulated puppets. Other technology included pyrotechnics, simulated earthquakes, optical illusions, trap doors, hoists, clockwork mechanisms and counterweights, compound pulleys, industrial springs, windlass systems, fireworks, candles, mirrors, and gunpowder (Normington, 2017).

This high level of participation and co-creation, both on the part of Sacri Monti pilgrims from local monasteries and medieval guild craftspeople whom supplied and created the technological pieces and environments, nicely fits with Espen Aarseth's concept of interactive texts (which can be broadly understood as including many kinds of experiences, including games) as necessitating "nontrivial effort” on the part of the participant (Aarseth 1997).

Democracity at the NYWF '39-' 40 as well as Norman Bel Geddes' Futurama at the same fair- both are representations of ideal future cities, designed on a radial plan and feature extensively developed highway systems, presaging the surging rise of the automobile in American culture. Democracity was designed by Henry Dreyfuss, and featured as the main exhibit at the center of the fair in the fair's 'Theme Center,' housed inside the giant sphere of the iconic Trylon and Perisphere duo which were also used as the fair logo. Futurama was commissioned by General Motors to promote their automobile lines as a corporate pavilion, and designed by Norman Bel Geddes. Futurama differed from Democracity in one major way: the Futurama experience was a ride. While visitors to the Democracity exhibit entered the Perisphere by walking up an enormous ramp known as the 'helicline,' and then strolled around the rotunda space on two slowly rotating platforms to observe a six minute light show with audio that animated the vast miniature scale model metropolis below, the Futurama visitors sat in single occupancy upholstered segments of a divided bench that rotated around the exhibit, with individual speakers piping audio in to each 'cabin' of the ride. The Futurama experience becomes more automated and individualized, in this way, and less participatory and communal than Democracity - perhaps appropriate given the corporate emphasis in the GM pavilion.

Again as in the 1939-1940 fair, a second more traditional diorama experience was on display as well, this time in urban planner and Fair president Robert Moses' Panorama exhibit. Presented in contrast with a model of New Amsterdam in 1660, The Panorama presented an up-to-date current scale model of Manhattan, showcasing the many ways in which Moses had reshaped the city (Sabat, 2014). The Panorama is still updated today, and remains housed in the Queens Museum in Flushing Meadows, at the fair site, and still provides a particular pleasure in its meticulous, analogue mediation of the city. The 'game' of the Panorama is to find yourself, or find your space in the model. This provides you with a new perspective on your surrounding context and relative size within that context. The viewer may not feel small in their 92nd street apartment, but when confronted with finding oneself in the Panorama, the viewer's smallness in comparison with the vastness of the rest of the model, and therefore the rest of the city, is striking. Somewhat undercutting 
the pleasure of the miniature, as discussed by Bachelard (Bachelard, 1969), the Panorama in particular underscores the power of the urban planner (Robert Moses) to reshape the environment and to dictate the trajectories inhabitants will, or rather infamously, won't take (Winner, 1980).

An interesting connection between these historical examples of interactive spatialized storytelling is that several represent virtual travel for users to spaces they have not physically visited before, such as Jerusalem, or travel to past times and events as in Christ's story, or virtual travel to imagined spaces like the projected future of Democracity. Robert Moses' Panorama is the only example in our set to present a mediated but accurate version of a lived space for the inhabitant to explore in miniature. In terms of co-constructed experiences, the York Mystery Plays provide an example that bears some similarity to contemporary games that also prioritize the player as designer, such as Minecraft, Terraria, Roblox, Second Life, etc., while the Sacri Monti examples give us tantalizing inspiration with their many multi-sensory strategies for creating an affective experience in immersive space. Reflecting on the complex literacies required by users (or players) of these interactive, immersive storyworlds, we can see that even in the pre-digital world, both designers and players have long been engaged in creating experiences we sometimes today characterize as unique to games. Illuminating this larger legacy, which can be extended yet further as Ryan, Foote and Azaryahu explore from literary text to narrative geography (Ryan et al., 2016) has the potential to open new territory for game based learning to mine in understanding player literacy processes as well as concepts fruitful for design decision making.

\section{CONCLUSION: UNDERSTANDING CONTEMPORARY LITERACY DISCOURSE}

When contrasting the rich history of literacy in other media to games, the definitions of literacy in games are comparatively lopsided in favour of the game artefact. A kind of techno-fetishization of the game object dominates, emphasizing its interactivity as a product of qualities such as procedurality and computation. This leads to an instrumentalized perspective on learning, reflective of the instrumentalist focus on the computational nature of the technological tool itself. While we do not mean to argue a flattening of the very real and material differences between computational media and others, we do suggest a transhistorical approach to understanding game based learning could provide needed nuance and breadth by tracing meaningful connections with pre-digital interactive media. This wider transhistorical perspective could yield exciting connections across many spheres, such as the history of playground design and theme parks (Biondo, 2014, Lukas, 2016), the enduring legacy of educational philosophies that prioritize the design of the environment such as the Montessori method (Montessori, 1936), and early visionary texts that describe conceptual designs for responsive, interactive learning environments (Bush, 1945, Nelson, 1987), to name a few.

In essence, dominant views in games research - and by extension game-based learning research - currently implicitly embrace an instrumentalist view of literacy. This both serves to obfuscate several shortcomings of digital games as a medium, but also places limitations on which topics are included in the discourse regarding digital game-based learning. Digital game-based learning is often described as a design challenge and uses the exact same vernacular as game designers and the games industry (e.g., Kiili, 2005; Kiili et al., 2014; Zarraonandia et al., 2012; Malone, 1980). It focuses on refining games as 'learning machines' (Gee, 2003), and discusses the various forms of 'stealth learning' (e.g., Sharp, 2012) or 'incidental learning' (e.g., Rodriguez, 2013) that designs will illicit; completely omitting active reflection and reading on part of the player in favour of the instrument's properties.

A broader understanding of literacy opens up digital game-based learning discussions to more critical perspectives; games are not uniquely ground-breaking in all matters of interaction or immersive interaction spaces. An expanded understanding of literacy has the potential to enable scholars to view games as an activity, object, setting, and/or performance that is intertwined in socioeconomic, cultural, and capitalist political traditions and contexts. As such, these literacies are also accessible then to other inter-disciplinary critical considerations for games: feminist and gender perspectives, inclusion and (dis-)ability studies, postcolonialist interpretations, embodiment and affect theory, for example. As phrased by Kalonaityte, 2014, instrumentalism "hides the people and processes that do not fit the ideals of the instrument's functionalities" (translated from Swedish). The concept of the 'digital native' in particular is a perfect embodiment of the erasure of the marginalized, nonconforming, non-normative or otherwise identity-resistant individual.

We are certainly not the first to voice these issues. Critiques against these perspectives in digital game-based learning were more clearly vocalised in the early ' 00 s - often by scholars outside the games community - but it has since (in the authors' experiences) subsided. A notable example is Ito's critique from her decades-long anthropological studies of children's' educational software:

Early edutainment developers hoped to put accessible technical tools in the hands of the disenfranchised, alleviating the oppressiveness of narrow notions of education. Instead, children's software became another site for addressing achievement anxiety in parents and for supporting achievement for children who seem to have been born into success. (Ito, 2009, p. 188)

Ito specifically writes about how the real-world functions of the computer hardware and software market significantly impacted and limited what digital game-based learning could do, and more importantly who it ran the risk of excluding. Another example is the work of Arnseth, 2006, who warned about the lack of instrument critique in games research and how it would reduce research to reacting to - or even promoting - industry trends rather than proactively critiquing and contextualizing them: "Uncritical depictions of games as well-designed learning environments is also problematic because such arguments can easily be refurbished to suit particular economic interests prevalent in the gaming industry." (Arnseth, 2006)

Viewing game literacy as the ability to manoeuvre in 'learning environments' does not help us understand digital games' actual pedagogical processes, impact on pedagogical process, nor their effect on childrens' learning situations (as opposed to learning outcomes). If, as pedagogical designers, we seek true enlightenment 
for students (and ourselves) we must move beyond an ontology of games that centres on instrumentality. If we intend for students to participate in their own transformational learning, not as spectators, but as true actors and co-creators, taking advantage of the immersive body-mind coupling virtual environments have the potential to facilitate, surely the frame of procedural rhetoric is too limiting for understanding game based learning and player literacies.

\section{REFERENCES}

Arnseth, H.C. (2006) "Learning to Play or Playing to Learn - A Critical Account of the Models of Communication Informing Educational Research on Computer Gameplay", Game Studies, [Online] Vol. 6, No. 1,

Bachelard, G. (1969). The Poetics of Space. Boston, MA: Beacon Press.

Belshaw, D. (2012, March 22) The essential elements of digital literacies. TEDxWarwick Retrieved from: https://www.youtube.com/watch?v=A8yQPoTcZ78

Biondo, B. (2014) Once Upon a Playground: A Celebration of Classic American Play grounds, 1920-1975. Lebanon, NH: ForeEdge University Press of New England.

von Borries, F., Walz, S. P., Böttger, M. Eds. (2007) Space Time Play: Computer Games, Architecture and Urbanism: The Next Level. Basel, Switzerland: Birkhäuser Architecture.

Buckingham, D., \& Burn, A. (2007). Game Literacy in Theory and Practice. Journal of Educational Multimedia and Hypermedia, 16(3), 323-349.

Bush, V. (1945) “As We May Think." In: The Atlantic Monthly, Vol. 176, No. 1. Pp. 101 108 .

Carr, D. (2007) "The Trouble with Civilization", in T. Krzywinska \& B. Atkins (eds), Videogame, Player, Text, Manchester University Press, Manchester, UK.

Cooper, N., Lockyer, L., \& Brown, I. (2013). Developing multiliteracies in a technologymediated environment. Educational Media International, 50(2), 93-107.

Crupi, G. (2019) "Volvelles of knowledge: Origin and Development of an instrument of scientific imagination (13th-17th centuries)." In: JLIS.it, 10:2, pp. 1-27.

Crupi, G. (2016) "Mirabilli visioni: from movable books to movable texts." In: JLIS.it, 7:1, pp. $25-87$

Van Eck, R. (2006) "Digital Game-Based Learning: It's Not Just the Digital Natives Who Are Restless", Educause review, Vol. 41, No. 2, pp 16-30.

Fotsch, P. M. (2001) "The Building of a Superhighway Future at the New York World's Fair." In: Cultural Critique, No. 48, Spring. Pp. 65 - 97.

Gee, J.P. (2003) What Video Games Have to Teach Us About Learning and Literacy, Palgrave Macmillan, New York.

Gee, J.P. (2005) "Learning by Design: Good Video Games as Learning Machines", ELearning and Digital Media, Vol. 2, No. 1, pp 5-16.

Gee, J. P., Hayes, E. R. (2011). Language and Learning in the Digital Age. Retrieved from http://www.eblib.com

Hague, C., \& Payton, S. (2010). Digital literacy across the curriculum. In Futurelab (Ed.), (pp. 2-58). Bristol, UK.

Hall, S. (1980) "Encoding/Decoding." In: Hall, S., Hobson, D., Lowe, A., Willis, P., Eds. Culture, Media, Language. London and New York: Routledge.

Ito, M. (2009) Engineering Play: A Cultural History of Children's Software, The MIT Press, Cambridge, MA.

Lukas, S., Ed. (2016) A Reader in Themed and Immersive Spaces. Pittsburgh, PA: Carnegie Mellon ETC Press.

Normington, K. (2017) “Technologies of Performance.” In: Enders, J., Ed. A Cultural History of Theatre in the Middle Ages. London and New York: Bloomsbury. Pp. 179 $-198$.

Malone, T.W. (1980) "What makes things fun to learn? heuristics for designing instructional computer games", Proceedings of the 3rd ACM SIGSMALL symposium and the first SIGPC symposium on Small systems, Palo Alto, California, United States, pp 162-169.

McLoughlin, C. (2011). What ICT-related skills and capabilities should be considered central to the definition of digital literacy?Paper presented at the World Conference on Educational Media and Technology 2011, Lisbon, Portugal. http://www.editlib. org/p/37908

Montessori, M. (1936) The Secret of Childhood. New York, NY: Ballantine Books.

Morshed, A. (2014) "Flying to the World of Tomorrow: The Ascension Theme at the 1939 New York World's Fair." In: Hollengreen, L, Pearce, C., Rouse, R., Schweizer, B., Eds. Meet Me At the Fair: A World's Fair Reader. Pittsburgh, PA: Carnegie Mellon ETC Press. Pp. 503 - 514.

Mukherjee, S. (2017) Videogames and Postcolonialsim: Empire Plays Back. London and New York: Palgrave MacMillan.

Nelson, T. (1987) Computer Lib / Dream Machines. Redmond, WA: Microsoft Press.

$\mathrm{Ng}, \mathrm{W}$. (2012). Can we teach digital natives digital literacy? Computers \& Education, 59(3), 1065-1078.

Nitsche, M. (2008) Video Game Spaces: Image, Play, and Structure in 3D Worlds. Cambridge, MA: MIT Press.

Nova, A. (1995) "'Popular' Art in Renaissance Italy: Early Response to the Holy Mountain at Varallo." In: Farago, C., Ed. Reframing the Renaissance: Visual Culture in Europe and Latin America 1450-1650. New Haven, CT: Yale University Press. Pp. $113-126$.

Kalonaityte, V. (2014) Normkritisk pedagogik: för den högre utbildningen, Studentlitteratur $\mathrm{AB}$, Lund.

Kiili, K., Lainema, T., de Freitas, S. and Arnab, S. (2014) "Flow framework for analyzing the quality of educational games", Entertainment Computing, Vol. 5, No. 4, pp 367-377.

Kiili, K. (2005) "Digital game-based learning: Towards an experiential gaming model", The Internet and Higher Education, Vol. 8, No. 1, pp 13-24.

Kirkpatrick, G. (2017) "How gaming became sexist: a study of UK gaming magazines 1981-1995", Media, Culture \& Society, Vol. 39, No. 4, pp 453-468.

Rodriguez, G. (2013) "Incidental Learning in a World of Warcraft Guild - A Case Study", 7th European Conference on Games-Based Learning, Vol. 2.

Ryan, M., Foote, K., Azaryahu, M. (2016) Narrating Space / Spatializing Narrative: Where Narrative Theory and Geography Meet. Columbus, OH: Ohio University Press.

Sabat, M. (2014) "Panorama: Robert Moses' Modern City and the New York World's Fairs.” In: Hollengreen, L, Pearce, C., Rouse, R., Schweizer, B., Eds. Meet Me At the Fair: A World's Fair Reader. Pittsburgh, PA: Carnegie Mellon ETC Press. Pp. 281 288.

Schweizer, B. (2009) Representations of the City in Video Games. Masters Thesis, Georgia Institute of Technology.

Schweizer, B. (2013) “Understanding the City in Video Games." Proceedings of DiGRA: Digital Games Research Association Conference.

Schweizer, B. (2014) Videogame Cities in Motion. Doctoral Dissertation, Georgia Institute of Technology.

Sharp, L.A. (2012) "Stealth Learning: Unexpected Learning Opportunities Through Games", Journal of Instructional Research, Vol. 1, pp 42-48.

Sicart, M. (2011) "Against Procedurality", Game Studies, [Online], Vol. 11, No. 3.

Terry-Fritsch, A. (2014) "Performing the Renaissance Body and Mind: Somaesthetic Style and Devotional Practice at the Sacro Monte Di Varallo." Open Arts Journal, Issue 4, Winter. Pp. 111 - 132.

Winner, L. (1980) “Do Artifacts Have Politics?” In: Daedalus, Vol.. 109, No. 1. Pp. 121 136.

Zarraonandia, T., Díaz, P., Ruíz, M.R. and Aedo, I. (2012) "Designing Educational Games by Combining Other Game Designs", 2012 IEEE 12th International Conference on Advanced Learning Technologies, 4-6 July 2012, pp 218-222. 